\title{
Impact of Apathy on Health-Related Quality of Life in Recently Diagnosed Parkinson's Disease: The ANIMO Study
}

\author{
Julián Benito-León, MD, PhD, ${ }^{1,2,3 *}$ Esther Cubo, MD, PhD, ${ }^{4}$ and Carlos Coronell, MD, $\mathrm{PhD},{ }^{5}$ on behalf of the \\ ANIMO Study Group \\ ${ }^{1}$ Department of Neurology, University Hospital "12 de Octubre", Madrid, Spain \\ ${ }^{2}$ Centro de Investigación Biomédica en Red sobre Enfermedades Neurodegenerativas, Madrid, Spain \\ ${ }^{3}$ Department of Medicine, Faculty of Medicine, Complutense University, Madrid, Spain \\ ${ }^{4}$ Department of Neurology, Hospital "General Yagüe," Burgos, Spain \\ ${ }^{5}$ Medical Advising Department, Boehringer Ingelheim España, Barcelona, Spain
}

\begin{abstract}
The impact of apathy on healthrelated quality of life (HRQOL) in recently diagnosed Parkinson's disease $(\mathrm{PD})$ has not been systematically investigated. The objective of this cross-sectional survey (ANIMO study) was to examine the contribution of apathy to $\mathrm{HRQOL}$ in a Spanish sample of recently diagnosed PD patients. PD patients, diagnosed within 2 years of inclusion, were recruited at 102 outpatient clinics in 82 communities throughout Spain. Apathy was quantified using the Lille Apathy Rating Scale and HRQOL with the EuroQol-5D questionnaire. A mean EuroQol-5D index score of 0.89 obtained from population references in Spain was used as the cutoff for this study. The relationship between apathy and the dichotomized EuroQol-5D index score ( $<0.89$ [lower HRQOL] vs $\geq 0.89$ [reference]) was examined using multiple logistic regression analysis, adjusting for sociodemographic and clinical variables. We consecu-
\end{abstract}

tively recruited 557 patients $(60.3 \%$ men) with a mean age of $68.8 \pm 9.7$ years. Apathy was diagnosed in 291 $(52.2 \%)$ and was related to problems in each of the EuroQoL dimensions. Apathetic PD patients showed EuroQol$5 \mathrm{D}$ index scores significantly lower than those without apathy $(0.64$ vs 0.83$)$. In an adjusted model, apathetic PD patients were 2.49 times more likely to have lower HRQOL than nonapathetic patients (odds ratio, 2.49; $95 \%$ confidence interval, 1.49-4.15, $P<0.01$ ). Apathy is very common in those with recently diagnosed $P D$ and is one of the major clinical determinants of HRQOL in this disease. It should be one of the primary concerns among clinicians who provide treatment to individuals affected by PD. (C) 2011 Movement Disorder Society

Key Words: apathy; Parkinson's disease; quality of life; EuroQol; Spain
Traditional medical models of impairment and disability provide an incomplete summary of disease burden. ${ }^{1,2}$ Hence, in recent years, measures of health-

\footnotetext{
*Correspondence to: Dr. Julián Benito-León, Avda. de la Constitución 73, portal 3, $7^{\circ}$ Izquierda, E-28821 Coslada, Madrid, Spain; jbenitol@ meditex.es

Funding agencies: The ANIMO was supported by an educational grant from Boehringer Ingelheim Spain.

Relevant conflicts of interest/financial disclosures: Julián Benito-León is supported by NIH R01 NS039422 from the National Institutes of Health (Bethesda, MD).

Full financial disclosures and author roles may be found in the online version of this article.
}

Received: 31 March 2011; Revised: 24 May 2011; Accepted: 15 June 2011

Published online 20 July 2011 in Wiley Online Library (wileyonlinelibrary.com). DOI: 10.1002/mds.23872

This article first published online 20 July 2011. The article has since changed. The phrase "than did participants who did not report any problems" was changed to "than participants who scored $\geq 0.89$." related quality of life (HRQOL) are increasingly being incorporated into studies of a variety chronic conditions, including neurodegenerative disorders. ${ }^{1-4}$ HRQOL involves those aspects of quality of life or function that are influenced by health status, and it is composed of distinct dimensions (ie, physical, psychological, and social aspects) that can be measured. ${ }^{1,2}$ In patients with Parkinson's disease (PD), HRQOL is an important focus of clinical practice and in treatment outcome studies. ${ }^{3,4}$ An outright cure for the disease still remains elusive, leaving patients with the challenges of living with a chronic medical condition. Thus, many potential factors could impair HRQOL in PD patients. Notably, motor dysfunction and depression are widely recognized as the main contributors to impairment of HRQOL in this chronic condition. ${ }^{5-7}$

Apathy is a common neuropsychiatric symptom that is increasingly recognized as another common 
B E N I T O - L E Ó N E T A L.

behavioral feature of PD. ${ }^{8}$ It is generally defined as a decrease in goal-directed behavior attributable to loss of motivation. ${ }^{8}$ Existing work supports the view that apathy and depression are distinct though sometimes overlapping constructs. ${ }^{8}$ Although there is growing evidence that apathy is one of the core nonmotor features of $\mathrm{PD},{ }^{8}$ little is known about its impact on HRQOL in the early stages of PD. There have been surprisingly few studies that have assessed this association in PD. For example, in the PRIAMO study, a multicenter Italian survey involving 1072 PD patients with a mean disease duration of 5.1 years, apathy was the symptom most associated with lower HRQOL.? One possible limitation of that study was that apathy was only assessed using 3 questions with dichotomous (yes/no) answers, without recourse to a validated instrument. ${ }^{9}$ In a study by Bottini et al, apathy was assessed in 57 PD patients with a mean disease duration of 7.5 years. In that study, ${ }^{10}$ the patients who reported apathy scored worse on the Parkinson's Disease and Quality of Life instrument than did those without apathy.

The impact of apathy on HRQOL in recently diagnosed PD therefore has not been systematically investigated. We examined the contribution of apathy to HRQOL in a large representative Spanish sample of recently diagnosed PD patients, using the Lille Apathy Rating Scale (LARS), a new instrument for detecting apathy. ${ }^{11}$ We hypothesized that apathy would be independently associated with decreased HRQOL in recently diagnosed PD cases.

\section{Patients and Methods}

\section{General Study Design}

The ANIMO Group was constituted in 2007 by a group of Spanish neurologists with expertise in PD. In that year, a study of apathy in a representative sample of patients with recently diagnosed PD was proposed: the ANIMO study. We sampled a series of patients from 102 Spanish PD outpatient clinics (see Acknowledgments section). These outpatient clinics were in 82 communities throughout Spain, thereby representing a broad geographic population. We chose these PD outpatient clinics because they maintain a computer-based registry of PD patients. We asked the participant neurologists to recruit a minimum of 6 consecutive PD patients who were coming to their clinic and who met the following criteria: PD diagnosed according to the United Kingdom Parkinson's Disease Society Brain Bank criteria, ${ }^{12}$ within 2 years of inclusion, and age $\geq$ 30 years. Patients with other types of parkinsonism were excluded, as were those with dementia according to Diagnostic and Statistical Manual of Mental Disorders Fourth Edition, Text Revision (DSM-IV-TR) crite- ria. ${ }^{13}$ A diagnosis of dementia was established on the basis of the medical history, an interview with the patient and a family member or caregiver, a general medical examination, results from laboratory tests, and diagnostic neuroimaging when needed. We excluded dementia patients because different studies have concluded that the validity of self-reported HRQOL is uncertain in dementia patients. ${ }^{14,15}$ In the early stages of dementia, some patients may give overly optimistic ratings of their capabilities and activities. ${ }^{16}$

For the purposes of this study, we asked the outpatient clinical neurologists to provide relevant medical information related to these patients, including age, sex, educational level, and medications. In addition, for each patient, the study physicians generated a list of all existing and past medical illnesses, detailed by organ systems, and a list of current and past treatments. We used the Cumulative Illness Rating Scale (CIRS) to measure the burden of medical comorbidity. ${ }^{17}$

Individuals received a clinical psychiatric interview, ${ }^{18}$ with current and past psychiatric diagnoses established according to the DSM-IV-TR using the Structured Clinical Interview for DSM-IV-TR Axis I Disorders. Diagnoses of symptomatic depression included major depressive episode, minor depression, and dysthymia. Depressive disorders in full remission (asymptomatic) were classified as nondepressed.

The Unified Parkinson's Disease Rating Scale (UPDRS) motor subscale ${ }^{19}$ and Hoehn and Yahr stage, ${ }^{20}$ both rated in the "on" state, provided measures of motor deficits and disease progression, respectively.

All procedures were approved by the Ethics Committee of "Complejo Asistencial Universitario" in Burgos, Spain. Written (signed) informed consent was obtained from all participants on enrollment. The study was designed as a cross-sectional survey. There were no treatment interventions during the course of this study.

\section{Instruments}

The EuroQoL is a standardized and validated generic measure of HRQOL that can be used in both healthy populations as well as in different groups of diseases, ${ }^{21,22}$ It is a useful measure of HRQOL in PD, reflecting severity and complications of the disease. ${ }^{4,23}$ The EuroQoL consists of 2 sections. $^{24}$ The first section (the EQ-5D) comprises 5 questions (items) relating to current problems in the dimensions "mobility," "selfcare," "usual activities," "pain/discomfort," and "anxiety/depression." Responses in each dimension are divided into 3 ordinal levels coded as: (1) no problems, (2) moderate problems, and (3) extreme problems. This part, called the EQ-5D descriptive system, provides a 5-dimensional description of health status. The EQ-5D generates 243 theoretically possible health states. 
Calculation of the EuroQol-5D index score was performed according to European recommendations. ${ }^{25}$ These scores express HRQOL quantitatively as a fraction of perfect health, with a score of 1 representing perfect health, a score of 0 representing death, and negative scores (minimum score -0.109) representing health states considered worse than death. The second section of the EuroQoL is a vertical visual analog scale (VAS), similar to a thermometer, ranging from 0 (worst imaginable health state) to 100 (best imaginable health state). The EQ VAS records the respondent's self-rated evaluation of health status (EQ VAS score). ${ }^{24}$

Apathy was assessed with the LARS. ${ }^{11}$ The LARS includes 33 items, divided into 9 domains (ie, reduction in everyday productivity, lack of interest, lack of initiative, extinction of novelty seeking, motivation, blunting of emotional responses, lack of concern, poor social life, and extinction of self-awareness). Each domain contributes equally to the global score. Items are scored yes/no except for the first 3 questions, which are scored on a 5-point Likert-type scale. Global LARS scores range from -36 to +36 , with higher scores indicating greater apathy. ${ }^{11}$ Standard validity indices showed that the LARS is sensitive and capable of distinguishing between apathy and depression. ${ }^{11}$ Apathy was defined here as a score on the LARS $\geq-16 .{ }^{11}$ Missing data were imputed by an individual mean method if missing data were $\leq 20 \%$ of the total. ${ }^{26,27}$

\section{Statistical Analyses}

Statistical analyses were performed in SPSS Version 18.0 (SPSS, Inc., Chicago, IL). All $P$ values are 2 tailed, and we considered $P<.05$ as significant. Proportions were compared using chi-square test or Fisher's exact test. As the continuous variables were not normally distributed, the Mann-Whitney test was used. Correlation coefficients were Spearman rank correlation coefficients. An association was considered high if the correlation coefficient $\left(r_{\mathrm{S}}\right)$ was $>0.50$, moderate if $0.35-0.50$, and weak if $<0.35 .^{28}$

As the number of respondents reporting "extreme problems" was small for all EQ-5D dimensions, the levels "moderate problems" and "extreme problems" were combined into 1 category ("problems"). On the other hand, as the EQ VAS score was not normally distributed (Kolmogorov-Smirnov, $P<.001$ ), even after log-transformation, linear regression analysis was not possible. Therefore, to assess the effects of possible confounders, we divided the EQ VAS score into 2 strata (lowest quartile score [worse HRQOL] vs all other scores [reference]).

An EuroQol-5D index score of 0.89, obtained from population references in Spain, was used as the cutoff point for this study. ${ }^{22}$ Multivariate logistic regression models were fitted to study (1) the association between EuroQol-5D index score $<0.89$ (lower HRQOL) ver- sus $\geq 0.89$ (reference), the dependent variable, and apathy, the independent variable; and (2) the association between the lowest quartile of the EQ VAS (reference $=$ all other scores), the dependent variable, with apathy, the independent variable. Significant associated covariates included age, sex, geographical area (rural vs urban), educational level (illiterate, primary studies, secondary or higher studies), marital status (single, married, widowed, and separated/divorced), occupational status (employed/unemployed [retired was classified as unemployed]), presence of caregiver, symptomatic depression without apathy (from now on will be referred to as "depression only"), UPDRS motor subscale score, Hoehn and Yahr stage, predominant PD motor impairment laterality (right, left, and both), motor fluctuations, dopaminergic agonist use, levodopa use, and comorbidity (CIRS total score). We began with an unadjusted model. Then, in an adjusted model, we considered all variables that in univariate analyses were associated with either apathy or EuroQol-5D index score $<0.89$ (lower HRQOL; reference $\geq 0.89$ ) or the lowest quartile of the EQ VAS (reference $=$ all other scores). These analyses generated odds ratios (ORs) with 95\% confidence intervals (CIs).

\section{Results}

Of the 677 PD patients who were deemed eligible for the study, $557(82.3 \%)$ were finally chosen. The remaining $120 \mathrm{PD}$ patients $(17.7 \%)$ were excluded because of insufficient medical information (eg, missing values on 1 or more UPDRS items). We compared the final sample of 557 cases with the 120 cases with insufficient medical information, and they were similar in age $(68.8 \pm 9.7$ vs $67.7 \pm 9.4$ years, Mann-Whitney; $P=.14)$ and sex (336 men [60.3\%] vs 67 men $\left.[55.8 \%] ; \chi^{2}=0.363, P=.41\right)$. Imputation for missing data of the LARS was carried out in 47 subjects $(8.4 \%$ of the final sample). The 557 PD patients were recruited between March 2007 and January 2009.

Mean age of PD patients was $68.8 \pm 9.7$ years, and 336 were men $(60.3 \%)$. PD duration was $1.3 \pm 0.6$ years. Apathy (LARS score $\geq-16$ ) was diagnosed in 291 patients $(52.2 \%)$ and any type of depression in 250 patients $(44.9 \%)$. Concomitant apathy and symptomatic depression was detected in 170 (30.5\%), apathy without symptomatic depression in 121 patients $(21.7 \%)$, and depression only in 80 (14.4\%). Of depressive patients, 31 (12.4\%) had major depression, $161(64.4 \%)$ minor depression, and 58 (23.2\%) dysthymia. Three hundred and fifty-seven patients $(64.1 \%)$ were on dopaminergic agonists, $332(59.6 \%)$ on levodopa (mean dose, $385.4 \pm 209.2 \mathrm{mg}$; range, 20-1250 mg), and $235(42.2 \%)$ on antidepressants. Among dopaminergic agonists, 255 patients (45.8\%) 
TABLE 1. Demographic and clinical characteristics of cohort stratified by apathy status

\begin{tabular}{|c|c|c|}
\hline & $\begin{array}{l}\text { Nonapathetic } \\
(\mathrm{n}=266)\end{array}$ & $\begin{array}{l}\text { Apathetic } \\
(\mathrm{n}=291)\end{array}$ \\
\hline $\operatorname{Age}^{\mathrm{a}}$ & $67.4 \pm 10.2(68.0)$ & $70.1 \pm 9.1(71.0)$ \\
\hline Sex (male) & $157(59.0 \%)$ & $179(61.5 \%)$ \\
\hline \multicolumn{3}{|l|}{ Geographical area } \\
\hline Rural area & $101(38.0 \%)$ & $96(33.0 \%)$ \\
\hline Urban area & $165(62.0 \%)$ & $195(67.0 \%)$ \\
\hline \multicolumn{3}{|l|}{ Educational level ${ }^{\mathrm{a}, \mathrm{c}}$} \\
\hline Illiterate & $11(4.1 \%)$ & 27 (9.3\%) \\
\hline Primary studies & 157 (59.0\%) & $193(66.8 \%)$ \\
\hline$\geq$ Secondary studies & $98(36.8 \%)$ & $69(23.9 \%)$ \\
\hline \multicolumn{3}{|l|}{ Marital status ${ }^{\mathrm{c}}$} \\
\hline Single & $18(6.8 \%)$ & $21(7.2 \%)$ \\
\hline Married or cohabitant & $198(74.7 \%)$ & $204(70.1 \%)$ \\
\hline Widowed & $41(15.5 \%)$ & $56(19.2 \%)$ \\
\hline Separated or divorced & $8(3.0 \%)$ & $10(3.4 \%)$ \\
\hline \multicolumn{3}{|l|}{ Occupational status } \\
\hline Employed & $48(18.0 \%)$ & $40(13.7 \%)$ \\
\hline Unemployed & $218(82.0 \%)$ & $251(86.3 \%)$ \\
\hline Presence of caregiver $^{\mathrm{b}, \mathrm{c}}$ & $128(48.7 \%)$ & $200(69.7 \%)$ \\
\hline $\begin{array}{l}\text { Presence of depression } \\
\text { only }^{\mathrm{b}}\end{array}$ & $80(30.1 \%)$ & $0(0.0 \%)$ \\
\hline UPDRS motor score ${ }^{b}$ & $17.1 \pm 8.5(15.0)$ & $24.8 \pm 11.3(24.0)$ \\
\hline \multicolumn{3}{|l|}{ Hoehn \& Yahr stage $\mathrm{e}^{\mathrm{b}}$} \\
\hline I & $170(63.9 \%)$ & $113(38.8 \%)$ \\
\hline$\|$ & $79(29.7 \%)$ & $132(45.4 \%)$ \\
\hline III & $16(6.0 \%)$ & $42(14.4 \%)$ \\
\hline IV & $1(0.4 \%)$ & $4(1.4 \%)$ \\
\hline \multicolumn{3}{|l|}{$\begin{array}{l}\text { Predominant laterality } \\
\text { of motor symptoms }{ }^{b}\end{array}$} \\
\hline Right & $142(53.4 \%)$ & $148(50.9 \%)$ \\
\hline Left & $105(39.5 \%)$ & $91(46.4 \%)$ \\
\hline Both & $19(7.1 \%)$ & $52(17.9 \%)$ \\
\hline $\begin{array}{l}\text { Presence of motor } \\
\text { fluctuations }\end{array}$ & $24(9.1 \%)$ & $48(16.6 \%)$ \\
\hline Dopaminergic agonist use & $168(63.2 \%)$ & $189(64.9 \%)$ \\
\hline Levodopa use $^{\mathrm{b}}$ & $128(48.1 \%)$ & $204(70.1 \%)$ \\
\hline Comorbidity (CIRS-G score) ${ }^{b}$ & $3.6 \pm 2.8(3.0)$ & $5.0 \pm 3.6(4.0)$ \\
\hline \multicolumn{3}{|l|}{ EuroQol-5D ${ }^{d}$} \\
\hline $\begin{array}{l}\text { Problems in dimension } \\
\text { "mobility"b }\end{array}$ & $105(39.5 \%)$ & $194(66.7 \%)$ \\
\hline $\begin{array}{l}\text { Problems in dimension } \\
\text { "self-care",b }\end{array}$ & $52(19.5 \%)$ & $133(45.7 \%)$ \\
\hline $\begin{array}{l}\text { Problems in dimension } \\
\text { "usual activities",b }\end{array}$ & $78(29.3 \%)$ & $186(63.9 \%)$ \\
\hline $\begin{array}{l}\text { Problems in dimension } \\
\text { "pain/discomfort"b }\end{array}$ & $118(44.4 \%)$ & $189(64.9 \%)$ \\
\hline $\begin{array}{l}\text { Problems in dimension } \\
\text { "anxiety/depression"b }\end{array}$ & $62(23.3 \%)$ & $182(62.5 \%)$ \\
\hline EQ VAS score ${ }^{b}$ & $68.1 \pm 16.2(70.0)$ & $56.9 \pm 18.6(60.0)$ \\
\hline EuroQol-5D index score ${ }^{b}$ & $0.83 \pm 0.17(0.87)$ & $0.64 \pm 0.26(0.66)$ \\
\hline
\end{tabular}

Mean \pm SD (median) and frequency (\%) are reported. Mann-Whitney $U$ test was used for comparisons of continuous data and the $\chi_{2}$ test or Fisher $\mathrm{p}$ for proportions. Cumulative Illness Rating Scale-Geriatrics $=\mathrm{CIRS}-\mathrm{G}$ score.

a $P<.01$

${ }^{\mathrm{b}} P<.001$;

${ }^{\mathrm{C}}$ Data on some participants were missing;

dpercentage of patients scoring moderate or extreme problems on each of the EuroQol-5D dimensions. were on pramipexole (mean dose, $2.06[2.1] \pm 0.9 \mathrm{mg}$ base vs $1.86[2.1] \pm 0.9 \mathrm{mg}$ base; $2.94[3] \pm 1.28 \mathrm{mg}$ salt vs 2.65 [3] $\pm 1.28 \mathrm{mg}$ salt), $53(9.5 \%)$ on ropinirole (mean dose, $10.20 \pm 5.65 \mathrm{mg}$; range, $2.0-24 \mathrm{mg}$ ), $36(6.5 \%)$ on rotigotine (mean dose, $8.22 \pm 3.30 \mathrm{mg}$; range, $2-16 \mathrm{mg})$, and $1(0.2 \%)$ on cabergoline $(2 \mathrm{mg}$ daily). Ten patients $(1.8 \%)$ were receiving both pramipexole and rotigotine, 1 patient $(0.2 \%)$ pramipexole and cabergoline, and 1 patient $(0.2 \%)$ ropinirole and rotigotine.

Compared with patients with apathy, nonapathetic patients were younger, more educated, and with lower motor severity impairment and rates of associated comorbid medical conditions (Table 1). In addition, they reported fewer problems in each one of the dimensions of the EQ-5D (Table 1). Mean scores on the EuroQol$5 \mathrm{D}$ index score and on the EQ VAS in apathetic recently diagnosed PD patients were significantly lower than those in nonapathetic patients (Table 1).

Using the dichotomized EuroQol-5D index score, there were significant differences between those who scored $<0.89$ (lower HRQOL) versus those who scored $\geq 0.89$ (Table 2). Overall, as expected, participants who scored $<0.89$ were significantly older, less educated, and had higher motor severity impairment and more medical comorbidity than participants who scored $\geq 0.89$. In addition, they were more likely to require a caregiver and to be unemployed (Table 2). After adjusting for age in years, sex, geographical area, educational level, occupational status, presence of caregiver, depression only, UPDRS motor score, Hoehn \& Yahr stage, predominant laterality of motor symptoms, motor fluctuations, levodopa use, and comorbidity, apathetic PD patients were 2.49 times more likely to have lower HRQOL (EuroQol-5D index score $<0.89$ ) than were nonapathetic PD patients (OR, 2.49; 95\% CI, 1.49-4.15; $P<.01$; Table 3 ).

As expected, those who rated their health state in the lowest quartile of the EQ VAS scored significantly higher on the LARS than those who rated their health status in the remaining quartiles (Table 4). Further, logistic regression analysis, adjusted for age in years, sex, educational level, marital status, occupational status, presence of caregiver, depression only, UPDRS motor score, Hoehn \& Yahr stage, predominant laterality of motor symptoms, motor fluctuations, levodopa use, and comorbidity, showed that apathetic PD patients tended to rate their health state significantly lower on the EQ VAS than did nonapathetic PD patients (Table 5).

The correlations observed between EuroQoL and LARS dimensions are presented in Table 6. Overall, there were significant, although weak to moderate, correlations between EuroQoL and LARS dimensions.

Imputation of data by an individual mean method may have improved the average apathy score. To assess this possibility, we conducted a sensitivity analysis. We 
A P A THY A N D

TABLE 2. Demographic and clinical characteristics of cohort stratified by EuroQol-5D index score

\begin{tabular}{|c|c|c|}
\hline & $\begin{array}{l}E Q-5 D<0.89 \\
\quad(n=422)\end{array}$ & $\begin{array}{l}E Q-5 D \geq 0.89 \\
\quad(n=135)\end{array}$ \\
\hline $\operatorname{Age}^{\mathrm{C}}$ & $69.7 \pm 9.3(71.0)$ & $66.0 \pm 10.4(67.0)$ \\
\hline Sex (male) ${ }^{\mathrm{a}}$ & $243(57.6 \%)$ & $93(68.9 \%)$ \\
\hline \multicolumn{3}{|l|}{ Geographical area $^{\mathrm{a}}$} \\
\hline Rural area & $159(37.7 \%)$ & $38(28.1 \%)$ \\
\hline Urban area & $263(62.3 \%)$ & 97 (71.9\%) \\
\hline \multicolumn{3}{|l|}{ Educational level $^{\mathrm{a}, \mathrm{d}}$} \\
\hline Illiterate & $28(6.7 \%)$ & $10(7.4 \%)$ \\
\hline Primary studies & $277(66.0 \%)$ & $73(54.1 \%)$ \\
\hline$\geq$ Secondary studies & $115(27.4 \%)$ & $52(38.5 \%)$ \\
\hline \multicolumn{3}{|l|}{ Marital status ${ }^{\mathrm{d}}$} \\
\hline Single & $25(5.9 \%)$ & $14(10.4 \%)$ \\
\hline Married or cohabitant & $301(71.5 \%)$ & $101(74.8 \%)$ \\
\hline Widowed & $80(19.0 \%)$ & $17(12.6 \%)$ \\
\hline Separated or divorced & $15(3.6 \%)$ & $3(2.2 \%)$ \\
\hline \multicolumn{3}{|l|}{ Occupational status ${ }^{\mathrm{a}}$} \\
\hline Employed & $59(14.0 \%)$ & $29(21.5 \%)$ \\
\hline Unemployed & $363(86.0 \%)$ & $106(78.5 \%)$ \\
\hline Presence of caregiver ${ }^{c, d}$ & $266(63.9 \%)$ & $62(46.3 \%)$ \\
\hline Presence of depression only & $63(14.9 \%)$ & $17(12.6 \%)$ \\
\hline \multicolumn{2}{|l|}{ Hoehn \& Yahr stage ${ }^{c}$} & $14.8 \pm 7.3(14.0)$ \\
\hline 1 & $193(45.7 \%)$ & $90(66.7 \%)$ \\
\hline$\|$ & $167(39.6 \%)$ & $44(32.6 \%)$ \\
\hline III & 57 (13.5\%) & $1(0.7 \%)$ \\
\hline IV & $5(1.2 \%)$ & $0(0.0 \%)$ \\
\hline \multicolumn{3}{|l|}{$\begin{array}{l}\text { Predominant laterality } \\
\text { of motor symptoms }\end{array}$} \\
\hline Right & $217(51.4 \%)$ & $73(54.1 \%)$ \\
\hline Left & $145(34.4 \%)$ & $51(37.8 \%)$ \\
\hline Both & $60(14.2 \%)$ & $11(8.1 \%)$ \\
\hline $\begin{array}{l}\text { Presence of motor } \\
\text { fluctuations }{ }^{b, d}\end{array}$ & $66(15.7 \%)$ & $6(4.4 \%)$ \\
\hline Dopaminergic agonist use & $279(66.1 \%)$ & $78(57.8 \%)$ \\
\hline Levodopa use $^{c}$ & $278(65.9 \%)$ & $54(40.0 \%)$ \\
\hline Comorbidity (CIRS-G score) ${ }^{\mathrm{C}}$ & $4.7 \pm 3.4(4.0)$ & $3.1 \pm 2.6(3.0)$ \\
\hline $\begin{array}{l}\text { Lille Apathy Rating Scale } \\
\text { total score }\end{array}$ & $-12.5 \pm 14.7(-6)$ & $-20.2 \pm 10.3(-21)$ \\
\hline
\end{tabular}

Mean \pm SD (median) and frequency (\%) are reported. Mann-Whitney $U$ test was used for comparisons of continuous data and $\chi_{2}$ test or Fisher $p$ for proportions. Cumulative Illness Rating Scale-Geriatrics = CIRS-G score. ${ }^{\text {a }} P<.05$;

${ }^{\mathrm{b}} \mathrm{P}<.01$

${ }^{\mathrm{c}} P<.001$;

${ }^{\mathrm{d} D a t a}$ on some participants were missing.

restricted the analysis to participants with complete LARS; in these analyses, we also found that apathy was associated with an EuroQol-5D index score $<0.89$ in unadjusted (OR, 3.25; 95\% CI, 2.10-5.02; $P<.001$ ) and adjusted (OR, 2.43; 95\% CI, 1.41-4.18; $P=.001$ ) models. Similarly, apathy was associated with the lowest quartile of the EQ VAS in unadjusted (OR, 3.42; 95\% CI, 2.26-5.16; $P<.001$ ) and adjusted (OR, 3.14; 95\% CI, 1.82-5.44; $P<.001)$ models.

\section{Discussion}

In this large multicenter nationwide cross-sectional study, apathy was associated with lower HRQOL in recently diagnosed PD. As we hypothesized, apathetic PD patients had an overall EuroQol-5D index score that was significantly lower than that of nonapathetic patients, even after controlling for potential confounding variables. Further, apathy was independently associated with the lowest quartile (lower HRQOL) of the EQ VAS.

The results of this study have several clinical implications. Apathy may be a marker of poor HRQOL in recently diagnosed $\mathrm{PD}$, even after adjusting for potential confounders, mainly depression. In addition, we also observed that apathetic PD patients reported more problems in each of the 5 dimensions of the EQ5D. This suggests that apathy might affect all spheres of a patient's subjective health status. Second, apathy is very prevalent among recently diagnosed PD patients. In our sample, more than $50 \%$ of patients were diagnosed with apathy. This percentage is comparable to that reported in a recent study by Oguru et $\mathrm{al}^{29}$ who found that $60 \%$ of $150 \mathrm{PD}$ patients were considered to have apathy. In the only case-control study of apathy in drug-naive patients with incident PD, apathy was found in $22.9 \% .^{30}$ One important question is: why is apathy so prevalent among recently diagnosed PD patients? The pathogenesis of apathy in this population has not been elucidated, but there is some evidence that it might be caused by a ventral striatal dopaminergic deficit and depletion of serotonin and norepinephrine, ${ }^{31-33}$ and these pathophysiological mechanisms are already found in the early phase of the parkinsonian state. ${ }^{32}$

There are certain limitations to our study that must be considered. First, the patients in the current study may represent a selected group of recently diagnosed PD patients (ie, patients seen in selected outpatient clinics), and hence it is questionable to what extent our results can be generalized to the entire early PD population. However, we recruited a large representative cross-section of the community-dwelling

TABLE 3. Apathy status (independent variable) and odds of EuroQol-5D index score $<0.89$ (dependent variable)

\begin{tabular}{cccccc}
\hline & \multicolumn{2}{c}{ Unadjusted } & & \multicolumn{2}{c}{ Adjusted } \\
\cline { 2 - 3 } \cline { 5 - 6 } & $\begin{array}{c}\text { Odds } \\
\text { ratio }\end{array}$ & $\begin{array}{c}95 \% \\
\mathrm{Cl}\end{array}$ & & $\begin{array}{c}\text { Odds } \\
\text { ratio }\end{array}$ & $\begin{array}{c}95 \% \\
\mathrm{Cl}\end{array}$ \\
\hline $\begin{array}{c}\text { Apathetic PD patients } \\
(\mathrm{n}=291)\end{array}$ & $3.19^{\mathrm{b}}$ & $2.11-4.82$ & & $2.49^{\mathrm{a}}$ & $1.49-4.15$ \\
$\begin{array}{c}\text { Nonapathetic PD patients } \\
(\mathrm{n}=266), \text { reference }\end{array}$ & 1.00 & - & & 1.00 & - \\
$\quad$ category & & & & & \\
\hline
\end{tabular}

Adjusted for age in years, sex, geographical area, educational level, occupational status, presence of caregiver, depression only, UPDRS motor score, Hoehn \& Yahr stage, predominant laterality of motor symptoms, motor fluctuations, levodopa use, and comorbidity.

${ }^{\mathrm{a}} P<.01 ;$

${ }^{\mathrm{b}} P<.001$. 
B E N I T O - L E Ó N E T A L .

TABLE 4. Demographic and clinical characteristics of cohort stratified by EQ-VAS quartiles

\begin{tabular}{|c|c|c|}
\hline & $\begin{array}{c}\text { Lowest quartile } \\
\text { of EQ VAS } \\
\text { (EQ VAS } \leq 50) \\
n=171\end{array}$ & $\begin{array}{l}\text { All other } \\
\text { scores, } \\
n=386\end{array}$ \\
\hline Age & $70.4 \pm 8.7(71.0)$ & $68.1 \pm 10.0(69.0)$ \\
\hline Sex (male) $)^{b}$ & $88(51.5 \%)$ & $248(64.2 \%)$ \\
\hline \multicolumn{3}{|l|}{ Geographical area } \\
\hline Rural area & $60(35.1 \%)$ & $137(35.5 \%)$ \\
\hline Urban area & $111(64.9 \%)$ & $249(64.5 \%)$ \\
\hline \multicolumn{3}{|l|}{ Educational level $\left.\right|^{b, d}$} \\
\hline Illiterate & $16(9.4 \%)$ & $22(5.7 \%)$ \\
\hline Primary studies & $118(69.0 \%)$ & $232(60.4 \%)$ \\
\hline$\geq$ Secondary studies & $37(21.6 \%)$ & $130(33.9 \%)$ \\
\hline \multicolumn{3}{|l|}{ Marital status ${ }^{\mathrm{b}, \mathrm{d}}$} \\
\hline Single & $14(8.2 \%)$ & $25(6.5 \%)$ \\
\hline Married or cohabitant & $107(62.6 \%)$ & $295(76.6 \%)$ \\
\hline Widowed & $42(24.6 \%)$ & $55(14.3 \%)$ \\
\hline Separated or divorced & $8(4.7 \%)$ & $10(2.6 \%)$ \\
\hline \multicolumn{3}{|l|}{ Occupational status ${ }^{\mathrm{C}}$} \\
\hline Employed & $16(9.4 \%)$ & $72(18.7 \%)$ \\
\hline Unemployed & $155(90.6 \%)$ & $314(81.3 \%)$ \\
\hline Presence of caregiver ${ }^{\mathrm{a}, \mathrm{d}}$ & $112(65.9 \%)$ & $216(56.8 \%)$ \\
\hline $\begin{array}{l}\text { Presence of depression } \\
\text { only }\end{array}$ & $19(11.1 \%)$ & $61(15.8 \%)$ \\
\hline UPDRS motor score ${ }^{\mathrm{c}}$ & $25.7 \pm 12.0(25.0)$ & $19.1 \pm 9.6(17.0)$ \\
\hline \multicolumn{3}{|l|}{ Hoehn \& Yahr stage ${ }^{c}$} \\
\hline I & $64(37.4 \%)$ & $219(56.7 \%)$ \\
\hline$\|$ & $73(42.7 \%)$ & $138(35.8 \%)$ \\
\hline III & $32(18.7 \%)$ & $26(6.7 \%)$ \\
\hline IV & $2(1.2 \%)$ & $3(0.8 \%)$ \\
\hline \multicolumn{3}{|l|}{$\begin{array}{l}\text { Predominant laterality } \\
\text { of motor symptoms }\end{array}$} \\
\hline Right & $88(51.5 \%)$ & $202(52.3 \%)$ \\
\hline Left & $49(28.7 \%)$ & $147(38.1 \%)$ \\
\hline Both & $34(19.9 \%)$ & $37(9.6 \%)$ \\
\hline $\begin{array}{l}\text { Presence of motor } \\
\text { fluctuations }^{\mathrm{d}}\end{array}$ & $29(17.0 \%)$ & $43(11.2 \%)$ \\
\hline Dopaminergic agonist use & $91(62.3 \%)$ & $239(65.7 \%)$ \\
\hline Levodopa use $^{\mathrm{a}}$ & 99 (67.8\%) & $201(55.2 \%)$ \\
\hline Comorbidity (CIRS-G score) ${ }^{b}$ & $5.1 \pm 3.6(4.0)$ & $4.0 \pm 3.1(3.0)$ \\
\hline $\begin{array}{l}\text { Lille Apathy Rating Scale } \\
\text { total score }\end{array}$ & $-5.1 \pm 14.9(-6)$ & $-15.6 \pm 13.0(-18)$ \\
\hline
\end{tabular}

Mean \pm SD (median) and frequency (\%) are reported. Mann-Whitney $U$ test was used for comparisons of continuous data and $\chi_{2}$ test or Fisher $p$ for proportions. Cumulative Illness Rating Scale-Geriatrics $=$ CIRS-G score.

a $P<.05$;

${ }^{\mathrm{b}} P<.01 ;$

${ }^{\mathrm{c}} P<.001$;

${ }^{d}$ Data on some participants were missing.

population of nondemented Spanish recently diagnosed PD patients. In Spain, health care is fully state subsidized, and community-dwelling PD subjects are mostly seen by hospital-based and hospital-associated neurologists. ${ }^{34-36}$ Second, we used a generic measure of HRQOL designed to measure quality-of-life outcomes for any disease or treatment as opposed to disease-specific dimensions. Although the EuroQoL has been shown to be a valid measure of HRQOL in $\mathrm{PD},{ }^{4,7,21}$ the instrument may nevertheless not reveal the full spectrum of symptoms and impairments asso-
TABLE 5. Apathy status (independent variable) and odds of lowest quartile of EQ VAS (dependent variable)

\begin{tabular}{|c|c|c|c|c|}
\hline & \multicolumn{2}{|c|}{ Unadjusted } & \multicolumn{2}{|c|}{ Adjusted } \\
\hline & $\begin{array}{l}\text { Odds } \\
\text { ratio }\end{array}$ & $\begin{array}{c}95 \% \\
\mathrm{Cl}\end{array}$ & $\begin{array}{l}\text { Odds } \\
\text { ratio }\end{array}$ & $\begin{array}{c}95 \% \\
\mathrm{Cl}\end{array}$ \\
\hline $\begin{array}{l}\text { Apathetic PD patients } \\
\quad(\mathrm{n}=291)\end{array}$ & $3.75^{\mathrm{a}}$ & $2.52-5.57$ & $3.62^{\mathrm{a}}$ & $2.15-6.11$ \\
\hline $\begin{array}{l}\text { Nonapathetic PD patients } \\
(\mathrm{n}=266) \text {, reference } \\
\text { category }\end{array}$ & 1.00 & - & 1.00 & - \\
\hline
\end{tabular}

Adjusted for age in years, sex, educational level, marital status, occupational status, presence of caregiver, depression only, UPDRS motor score, Hoehn \& Yahr stage, predominant laterality of motor symptoms, motor fluctuations, levodopa use, and comorbidity.

${ }^{\mathrm{a} P}<.001$

ciated with PD. However, in the conduct of PD studies, there are few instruments better suited for qualityof-life evaluation than the EuroQoL. ${ }^{4,7,23}$ Further, we chose the EuroQoL because of its brevity, acceptability for routine and repetitive administration, and suitability for cost-utility studies both in PD patients and in patient populations with other disease conditions. Third, there are important potentially relevant nonclinical risk factors that were not assessed in our study, including the overall quality of the PD care delivered. Fourth, residual confounding by unmeasured variables in the multivariate analyses of HRQOL determinants is possible. Fifth, the use of a cross-sectional design leaves us more susceptible to confounding variables; however, it also enables us to generate hypotheses that should be confirmed in further studies. Finally, PD patients were not evaluated using detailed neuropsychological testing. Of interest is that Pluck and Brown ${ }^{37}$ reported that highly apathetic, nondemented PD patients performed worse than their less apathetic counterparts, especially in tasks evaluating

TABLE 6. Matrix of correlations (Spearman rank correlation coefficients) among the Lille Apathy Rating Scale and EuroQol

\begin{tabular}{lcc}
\hline & \multicolumn{2}{c}{ EuroQoL } \\
\cline { 2 - 3 } \multicolumn{1}{c}{ Lille Apathy Rating Scale } & $\begin{array}{c}\text { EuroQol-5D } \\
\text { index score }\end{array}$ & $\begin{array}{c}\text { Vertical visual } \\
\text { analog scale }\end{array}$ \\
\hline Reduction in everyday productivity & $0.428^{\mathrm{b}}$ & $0.335^{\mathrm{b}}$ \\
Lack of interest & $0.418^{\mathrm{b}}$ & $0.319^{\mathrm{b}}$ \\
Lack of initiative & $0.460^{\mathrm{b}}$ & $0.373^{\mathrm{b}}$ \\
Extinction of novelty seeking & $0.321^{\mathrm{b}}$ & $0.320^{\mathrm{b}}$ \\
Motivation & $0.487^{\mathrm{b}}$ & $0.420^{\mathrm{b}}$ \\
Blunting of emotional responses & $0.218^{\mathrm{b}}$ & $0.154^{\mathrm{b}}$ \\
Lack of concern & $0.210^{\mathrm{b}}$ & $0.126^{\mathrm{a}}$ \\
Poor social life & $0.352^{\mathrm{b}}$ & $0.292^{\mathrm{b}}$ \\
Extinction of self awareness & $0.288^{\mathrm{b}}$ & $0.210^{\mathrm{b}}$ \\
\hline
\end{tabular}

${ }^{\mathrm{a} P}<.01 ;$

${ }^{\mathrm{b}} P<.001$. 
executive functions. Our study was not designed to draw conclusions about the relationship between apathy and executive function. The presence of patients with mild cognitive impairment might have lessened the likelihood of valid ratings of the apathy. However, based on the original validation study in which the authors demonstrated that the LARS had satisfactory clinimetric properties, even with the inclusion of demented PD patients, ${ }^{11}$ we think that such potential rating errors were likely to be low.

This study also has several strengths. First, we attempted to adjust for the effects of many potential confounders. Second, we used modern statistical methods to deal with the challenge of missing data of the LARS. People with worse apathy scores tend to be the persons with missing data. Hence, excluding them would have provided artificially better mean scores. ${ }^{38}$ Third, we determined the impact of apathy in a population of recently diagnosed PD patients already on treatment. This avoided bias of treatment status on HRQOL. Our results may therefore be extrapolated to the PD community to some degree. Finally, weights used for the EuroQol-5D index estimation were obtained from the general population of Spain. ${ }^{22}$

In summary, apathy is very common in those with recently diagnosed PD and is one of the major clinical determinants of HRQOL in this disease. Clearly, apathy should be one of the primary concerns among clinicians who provide treatment to individuals affected by PD. Furthermore, in-depth assessment of apathy should be incorporated as an outcome measure in clinical trials.

Acknowledgments: We gratefully acknowledge the vital help of the other members of the ANIMO Study Group: Rosa Rodríguez-Fernández (Orense Hospital Complex, Orense, Orense); Robustiano PegoReigosa and José Manuel Paz-González (Calde General Hospital, Lugo, Lugo); Ernesto Cebrián-Pérez and Paula Suarez-Gil (Pontevedra Hospital Complex, Pontevedra); José Marey-López, Enrique Corredera-García, Francisco Javier López-González, Xiana Rodríguez-Osorio, and Susana Arias-Rivas (Santiago de Compostela University Hospital Complex, Santiago de Compostela, La Coruña); $\mathrm{M}^{\mathrm{a}}$ Carmen Lema (La Coruña Hospital Complex, La Coruña, La Coruña); Joaquín Peña (Hospital "San Agustín," Avilés, Asturias); Esther Suarez, (Jove Hospital, Gijón, Asturias); Dulce $\mathrm{M}^{\mathrm{a}}$ Solar-Sánchez (Cabueñes Hospital, Gijón, Asturias); José Antonio Vidal-Sánchez (Hospital "Valle del Nalón," Langreo, Asturias); Alberto Bergareche (Bidasoa Hospital, Fuenterrabía, Guipúzcoa); Javier Ruiz (Donostia Hospital, San Sebastián, Guipúzcoa); Juan Carlos Gómez-Esteban and José Manuel Losada (University Hospital "de Cruces," Bilbao, Vizcaya); José Manuel Fernández-García and Luis Carlos Álvaro-González (Basurto Hospital, Bilbao, Vizcaya); José Luis Sánchez-Menoyo and Javier Ruiz-Oseda (Galdakao Hospital, Galdakao, Vizcaya); Gerardo J. Soriano (Navarra Hospital, Pamplona, Navarra); María Martín-Bujanda (University Hospital "Virgen del Camino," Pamplona, Navarra); Ángel Fernández-Díaz (Hospital "El Bierzo," Ponferrada, León); Manuel A. Mazabel-Flores (Obra Hospitalaria "Nuestra Señora de Regla," León); Oscar Llamazares de La Fuente ("San Francisco" Clinic, León); María Dolores Sevillano and Jesús Arcaya (Salamanca University Hospital, Salamanca, Salamanca); Ana Belén Caminero (Hospital "Nuestra Señora de Sonsoles," Ávila, Avila); Wadih Bowakim (University Hospital "Río Hortega," Valladolid, Valladolid); Oscar Vega-López (Red Cross Central Hospital "San José y Santa Adela," Madrid, Madrid); $M^{\mathrm{a}}$ José Catalán, Javier del Val and Rocío García-Ramos (University Clinic Hospital "San Carlos," Madrid, Madrid); Esteban Francisco-Peña (La Moraleja Sanitas Hospital, Madrid, Madrid); Pedro Emilio Bermejo and Manuel Lara (University Hospital "La Paz," Madrid, Madrid); Mireya Losada and Lydia López-Manzanares (University Hospital "La Princesa," Madrid, Madrid); Alberto
Esquivel (Hospital "Infanta Leonor," Madrid, Madrid); Ignacio J. Posada, José Antonio Molina-Arjona, and Jerónimo Almajano (University Hospital "12 de Octubre," Madrid, Madrid); Mireya Losada López (Henares Hospital, Coslada, Madrid); Marina Mata and Pilar SánchezAlonso (University Hospital "Puerta del Hierro," Majadahonda, Madrid); David Andrés Pérez and Loreto Ballesteros (Hospital "Infanta Cristina," Parla, Madrid); Inmaculada Puertas (University Hospital "Príncipe de Asturias," Alcalá de Henares, Madrid); José Jesús Balseiro (Getafe University Hospital, Getafe, Madrid); Fernando Alonso-Frech (Fuenlabrada University Hospital, Fuenlabrada, Madrid); María del Mar Morín and José Miguel Velázquez-Pérez (Hospital "Virgen de la Salud," Toledo, Toledo); José Manuel Fernández-Carril (Guadalajara University Hospital, Guadalajara, Guadalajara); Marta Recio-Bermejo (General Hospital "De la Mancha Centro," Alcázar de San Juan, Ciudad Real); Ramón Ibáñez and Julia Vaamonde (Ciudad Real General Hospital, Ciudad Real, Ciudad Real); Jorge Artal (University Hospital "Miguel Servet”, Zaragoza, Zaragoza); Elena López-García (University Clinic Hospital "Lozano Blesa", Zaragoza, Zaragoza); Daniel Segarra (Alcañiz Hospital, Alcañiz, Teruel); Laura González- Mera (Viladecans Hospital, Viladecans, Barcelona); Jorge Hernández-Vara (Mutua de Terrassa Hospital, Terrassa, Barcelona); Ana $\mathrm{M}^{\mathrm{a}}$ Jaén-Peraire, (Game Medical Center, Sant Boi de Llobregat, Barcelona); Lourdes Ispierto-González and Laura Dorado-Bovix (Badalona Municipality Hospital, Badalona, Barcelona); José $\mathrm{M}^{\mathrm{a}}$ Soler (Hospital Sant Bernabé, Berga, Barcelona); Alfonso Moral and Elisabeth Franquet-Gómez (Hospital "Sant Camil", San Pedro de Ribas, Barcelona); Teresa Bernal (MIPS Private Foundation, Igualada, Barcelona); Tania Delgado (Hospital "Parc Taulí”, Sabadell, Barcelona); Matilde Calopa (Bellvitge University Hospital "Princeps d'Espanya", L'Hospitalet de Llobregat, Barcelona); Juan Bello-López (L'Hospitalet General Hospital, L'Hospitalet de Llobregat, Barcelona); Carlos Oliveras-Ley (University Hospital “del Mar”, Barcelona); Vicente Jesús García-Gil (CAP Quevedo, Barcelona); Antonio Palasí, Oriol de Fabregues, and Antonio Callen (University Hospital "Vall d'Hebron", Barcelona, Barcelona); Berta Pascual-Sedano (University Hospital "Sant Pau", Barcelona); Albert Lladó Plarrumani and Yolanda Blanco (University Clinic Hospital, Barcelona, Barcelona); Ana Malagelada (Barcelona Neurological Institute, Barcelona); Cesar Castejón ("Sagrada Familia" Clinic, Barcelona, Barcelona); Alain Luna-Rodríguez (Palamós Hospital, Palamós, Gerona); Raúl Martínez-Fernández and Olga Carmona (Figueras Hospital, Figueras, Gerona); Fabián Márquez (Hospital "Sant Jaume", Olot, Gerona); Josep M. Olivé Plana (San Juan University Hospital, Reus, Tarragona); Francisco Purroy-García (University Hospital "Arnau de Vilanova," Lérida, Lérida); Juan José Baiges-Octavio (Tortosa Hospital "Verge de la Cinta," Tortosa, Tarragona); Jesús Vega and Verónica González (Hospital "Ciudad de Jaén,” Jaén, Jaén); Carlos Sánchez-Ortiz and Fernando Sánchez-López (University Hospital "Reina Sofía," Córdoba); Víctor M. Campos (Xanit International Hospital, Benalmádena, Málaga); Francisco Pérez (University Clinic Hospital "Virgen de la Victoria," Málaga, Málaga); Fernando Vázquez ("Del Poniente" Policlinic, El Ejido, Almería); Juan Jesús Rodríguez (Instituto Especialidades Neurológicas-Virgen Rocío, Sevilla); Francisco Villalobos and Manuel Carballo (University Hospital "Virgen del Rocío," Sevilla, Sevilla); José Manuel García-Moreno, M ${ }^{a}$ Dolores Morales-Martínez, and Jorge Patrignani-Ochoa (University Hospital "Virgen de la Macarena," Sevilla, Sevilla); Francisca Terriza (Hospital "Santa María del Puerto," El Puerto de Santa María, Cádiz); Juan José Asencio (Puerto Real University Hospital, Puerto Real, Cádiz); Carmen García, Francisco Delgado-López, and Nuria Rodríguez-Fernández (Jerez Hospital, Jerez de la Frontera, Cádiz); Francisco Escamilla and María José Pérez-Navarro (University Hospital "Virgen de las Nieves," Granada); Fernando Castellanos and Bernardo Cueli (Hospital "Virgen del Puerto," Plasencia, Cáceres); Montserrat Gómez (Hospital "San Pedro de Alcántara," Cáceres, Cáceres); José María Ramírez-Moreno (University Hospital "Infanta Cristina," Badajoz, Badajoz); Joaquín Gómez-Espuch (University General Hospital "Morales Meseguer," Murcia); M ${ }^{a}$ Purificación Salmerón and José Manuel Rodríguez (University General Hospital "Reina Sofia," Murcia, Murcia); Ossama Morsi-Hassan and José Eustasio Meca-Lallana (University Hospital "Virgen de la Arrixaca," Murcia, Murcia); Sebastián MartínBalbuena (Cieza Hospital Foundation, Cieza, Murcia); Eva Fages-Caravaca (University Hospital "Santa María del Rosell," Cartagena, Murcia); Antonio Candeliere-Merlicco (Hospital "Rafael Méndez," Lorca, Murcia); Ayoze González-Hernández and José A. Suarez-Muñoz (Grand Canary University Hospital "Dr Negrín," Las Palmas de Gran Canaria, Islas Canarias); José Motias-Arbelo, University Hospital "Insular Gran Canaria," Las Palmas de Gran Canaria, Islas Canarias); Francisco Javier Carrillo-Padilla (Canary Islands University Hospital, Tenerife, Islas Canarias); Jesús Norelis Lorenzo-Brito (University Hospital "Nuestra Señora de Candelaria, Santa Cruz de Tenerife, Islas Canarias); Juan Manuel Callejo-Domínguez (Hospital "Vega Baja Orihuela," Orihuela, Alicante); $\mathbf{M}^{\mathrm{a}}$ José Sáenz (Elche University General Hospital, Elche, Alicante); Vicente Medrano-Martínez (Elda General Hospital, Elda, Alicante); $\mathrm{M}^{\mathrm{a}}$ Dolores Castaño Pérez (San Juan University Hospital, San Juan de Alicante, Alicante); Gema Mas-Sesé (Marina Baixa-Villajoyosa Hospital, Villajoyosa, Alicante); María José Monzón- Minguillod 
(Requena Hospital, Requena, Valencia); Antonio Salvador-Aliaga, Dolores Alonso Salvador, and Vicente Peset-Mancebo (Valencia University Clinic Hospital, Valencia, Valencia); Carlos Perla-Muedra and Caridad Valero-Merino (University Hospital "Arnau de Vilanova," Valencia, Valencia); Pilar Taberner-Andres (University Hospital "Dr. Peset," Valencia, Valencia); Emilio Meneu-García (La Plana Hospital, Castellón de la Plana, Castellón de la Plana); Elena Pajarón and Berta Claramonte Clausell (Castellón General Hospital, Castellón de la Plana, Castellón de la Plana); Fritz Nobbe (Juaneda Clinic, Palma de Mallorca, Palma de Mallorca); Jorge Eloy Elices-Palomar (Rotger Clinic, Palma de Mallorca, Palma de Mallorca); and Antonio García Trujillo (Neurologic Center, Palma de Mallorca, Palma de Mallorca). Finally, we also acknowledge the contribution provided by Drs. Elan D. Louis and Alex J. Mitchell, who critiqued late-stage drafts of the article.

\section{References}

1. Mitchell AJ, Benito-León J, González JM, Rivera-Navarro J. Quality of life and its assessment in multiple sclerosis: integrating physical and psychological components of wellbeing. Lancet Neurol. 2005;4:556-566.

2. Benito-León J, Morales JM, Rivera-Navarro J, Mitchell A. A review about the impact of multiple sclerosis on health-related quality of life. Disabil Rehabil. 2003;25:1291-1303.

3. Martínez-Martín P. An introduction to the concept of "quality of life in Parkinson's disease." J Neurol. 1998;245(Suppl 19):S2-S6.

4. Martínez-Martín P, Benito-León J, Alonso F, Catalán MJ, Pondal $\mathrm{M}$, Zamarbide I. Health-related quality of life evaluation by proxy in Parkinson's disease: approach using PDQ-8 and EuroQoL-5D. Mov Disord. 2004;19:312-318.

5. Forsaa EB, Larsen JP, Wentzel-Larsen T, Herlofson K, Alves G. Predictors and course of health-related quality of life in Parkinson's disease. Mov Disord. 2008;23:1420-1427.

6. Soh SE, Morris ME, McGinley JL. Determinants of health-related quality of life in Parkinson's disease: a systematic review. Parkinsonism Relat Disord. 2011;17:1-9.

7. Winter Y, von Campenhausen S, Gasser J, et al. Social and clinical determinants of quality of life in Parkinson's disease in Austria: a cohort study. J Neurol. 2010;257:638-645.

8. Richard IH. Depression and apathy in Parkinson's disease. Curr Neurol Neurosci Rep, 2007;7:295-301.

9. Barone P, Antonini A, Colosimo C, et al; PRIAMO study group. The PRIAMO study: a multicenter assessment of nonmotor symptoms and their impact on quality of life in Parkinson's disease. Mov Disord. 2009;24:1641-1649.

10. Bottini Bonfanti A, Etcheverry JL, Persi GG, Zezza H, Starkstein S, Gatto EM. [Apathy in Parkinson's disease. Impairment in quality of life]. Medicina (B Aires). 2009;69:253-258.

11. Sockeel P, Dujardin K, Devos D, Denève C, Destée A, Defebvre L. The Lille apathy rating scale (LARS), a new instrument for detecting and quantifying apathy: validation in Parkinson's disease. J Neurol Neurosurg Psychiatry. 2006;77:579-584.

12. Daniel SE, Lees AJ. Parkinson's Disease Society Brain Bank, London: overview and research. J Neural Transm Suppl. 1993;39: $165-172$.

13. American Psychiatric Association. Diagnostic and Statistical Manual of Mental Disorders. 4th Edition, Text Revision (DSM-IVTR). Washington, DC: American Psychiatric Association; 2000.

14. Coucill W, Bryan S, Bentham P, Buckley A, Laight A. EQ-5D in patients with dementia: an investigation of inter-rater agreement. Med Care. 2001;39:760-771.

15. Schiffczyk C, Romero B, Jonas C, Lahmeyer C, Müller F, Riepe MW. Generic quality of life assessment in dementia patients: a prospective cohort study. BMC Neurol. 2010;10:48.

16. Vogel A, Stokholm J, Gade A, Andersen BB, Hejl AM, Waldemar G. Awareness of deficits in mild cognitive impairment and Alzheimer's disease: do MCI patients have impaired insight? Dement Geriatr Cogn Disord. 2004;17:181-187.

17. Linn BS, Linn MW, Gurel L. Cumulative Illness Rating Scale. J Am Geriatr Soc. 1968;16:622-626.
18. First MB, Spitzer RL, Gibbon M, et al. Structured Clinical Interview for DSM-IV-TR Axis I Disorders, Research Version, Patient Edition. (SCID-I/P) New York: Biometrics Research, New York State Psychiatric Institute; 2002.

19. Fahn S, Elton RL. Members of the UPDRS Development Committee. Unified Parkinson's Disease Rating Scale. In: Fahn S, Marsden CD, Goldstein M, eds. Recent Developments in Parkinson's Disease II. New York: Macmillan; 1987:153-163.

20. Hoehn MM, Yahr MD. Parkinsonism: onset, progression, and mortality. Neurology. 1967;17:427-442.

21. EuroQol Group. EuroQol-a new facility for the measurement of health-related quality of life. Health Policy. 1990;16:199-208.

22. Badia X, Schiaffino A, Alonso J, Herdman M. Using the EuroQoI 5 -D in the Catalan general population: feasibility and construct validity. Qual Life Res 1998;7:311-322.

23. Schrag A, Selai C, Jahanshani M, Quinn N. The EQ-5D—a generic quality of life measure-is a useful instrument to measure quality of life in patients with Parkinson's disease. J Neurol Neurosurg Psychiatry. 2000;69:67-73.

24. [No authors listed]. EuroQol—a new facility for the measurement of health-related quality of life. The EuroQol Group. Health Policy. 1990;16:199-208.

25. Badia X, Roset M, Herdman M, Kind P. A comparison of United Kingdom and Spanish general population time trade-off values for EQ-5D health states. Med Decis Making. 2001;21:7-16.

26. Shrive FM, Stuart H, Quan H, Ghali WA. Dealing with missing data in a multi-question depression scale: a comparison of imputation methods. BMC Med Res Methodol. 2006;6:57.

27. Benito-León J, Rivera-Navarro J, Guerrero AL, et al; caregiver quality of life in multiple sclerosis (CAREQOL-MS) Study Group. The CAREQOL-MS was a useful instrument to measure caregiver quality of life in multiple sclerosis. J Clin Epidemiol. 2011;64: 675-686.

28. Juniper EF, Guyatt GH, Jaeschke R. How to develop and validate a new health-related quality of life instrument. In: Spilker B, ed. Quality of Life and Pharmacoeconomics in Clinical Trials. 2nd ed. Philadelphia: Lippincott-Raven Publishers; 1996:49-56.

29. Oguru M, Tachibana H, Toda K, Okuda B, Oka N. Apathy and depression in Parkinson disease. J Geriatr Psychiatry Neurol. 2010; 23:35-41.

30. Pedersen KF, Alves G, Brønnick K, Aarsland D, Tysnes OB, Larsen JP. Apathy in drug-naïve patients with incident Parkinson's disease: the Norwegian ParkWest study. J Neurol. 2010;257:217-223.

31. Rodriguez-Oroz MC, Jahanshahi M, Krack P, et al. Initial clinical manifestations of Parkinson's disease: features and pathophysiological mechanisms. Lancet Neurol. 2009;8:1128-1139.

32. Kulisevsky J, Pagonabarraga J, Pascual-Sedano B, Garcia-Sanchez $\mathrm{C}$, Gironell A. Prevalence and correlates of neuropsychiatric symptoms in Parkinson's disease without dementia. Mov Disord. 2008; 23:1889-1896.

33. Remy P, Doder M, Lees A, Turjanski N, Brooks D. Depression in Parkinson's disease: loss of dopamine and noradrenaline innervation in the limbic system. Brain. 2005;128:1314-1322.

34. Benito-León J, Bermejo-Pareja F, Rodriguez J, Molina JA, Gabriel $\mathrm{R}$, Morales JM. Prevalence of PD and other types of parkinsonism in three elderly populations of central Spain. Mov Disord. 2003; $18: 267-274$.

35. Benito-León J, Bermejo-Pareja F, Morales-Gonzalez JM, et al. Incidence of Parkinson disease and parkinsonism in three elderly populations of central Spain. Neurology. 2004;62:734-741.

36. Benito-León J, Porta-Etessam J, Bermejo F. [Epidemiology of Parkinson disease]. Neurologia. 1998;13(Suppl 1):2-9.

37. Pluck GC, Brown RG. Apathy in Parkinson's disease. J Neurol. Neurosurg Psychiatry. 2002;73:636-642.

38. Mayo NE, Fellows LK, Scott SC, Cameron J, Wood-Dauphinee S. A longitudinal view of apathy and its impact after stroke. Stroke. 2009;40:3299-3307. 